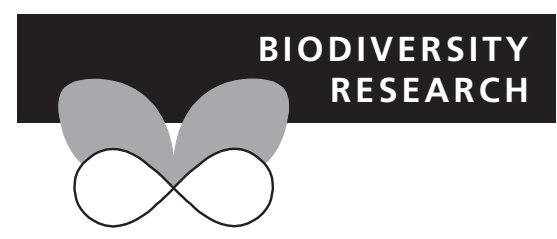

\title{
Evolutionary history of the endangered shrub snapdragon (Galvezia leucantha) of the Galápagos Islands
}

\author{
Beatriz Guzmán ${ }^{1}$ (iD, Ruben Heleno ${ }^{2}$, Manuel Nogales ${ }^{3}$, \\ Walter Simbaña ${ }^{4}$, Anna Traveset ${ }^{5}$ and Pablo Vargas ${ }^{1 *}$
}

\begin{abstract}
${ }^{1}$ Department of Biodiversity and Conservation, Real Jardín Botánico - CSIC, Plaza de Murillo 2, 28014 Madrid, Spain,

${ }^{2}$ Centre for Functional Ecology, Department of Life Sciences, University of Coimbra, 3000-213 Coímbra, Portugal, ${ }^{3}$ Island Ecology and Evolution Research Group, Instituto de Productos Naturales y Agrobiología - CSIC, Av. Astrofisico Francisco Sánchez, 3, 38206, San Cristóbal de La Laguna, Santa Cruz de Tenerife, Tenerife, Spain, ${ }^{4}$ Faculty of Food Science and Engineering, Universidad Técnica de Ambato, Colombia 02-11, Ambato EC180105, Ecuador, ${ }^{5}$ Department of Biodiversity and Conservation, Institut Mediterrani d'Estudis Avançats - CSIC, Carrer de Miquel Marquès, 21, 07190 Esporles, Mallorca, Spain
\end{abstract}

\begin{abstract}
Aim The endangered Galápagos shrub snapdragon (Galvezia leucantha, Antirrhineae, Plantaginaceae) is restricted to small populations on four islands. In this study, we appraised results from taxonomy, genetics, phylogenetics, phylogeography and pollination ecology to reconstruct the evolutionary history of the genus Galvezia.
\end{abstract}

Location Peru, continental Ecuador and Galápagos.

Methods We sequenced the nuclear ribosomal ITS and two plastid regions, $n d h F$ and $n d h F-r p L 32$, to infer the origin of Galvezia and patterns of colonization to and across the Galápagos archipelago, based on Bayesian inference and statistical parsimony analyses. To investigate genetic diversity and differentiation within G. leucantha, we screened the genome of six populations and obtained 194 AFLP fingerprints. Autogamy tests and pollination network analyses were performed to evaluate the colonization potential and to investigate the structure of the pollinators' assemblage of Galvezia.

Results Relationships of seven nucleotide-substitution haplotypes and 11 nucleotide-substitution ribotypes of Galvezia revealed monophyly for the Galapagos species. Dating estimates indicated divergence of the insular Galvezia lineage in the Middle-Upper Pleistocene (0.66-0.09 Ma). In addition, distribution of genotypes (seven haplotypes, eight ribotypes) across the three continental species showed geographical differentiation, while low differentiation and distribution of G. leucantha. AFLP genetic diversity is relatively high $\left(H_{\mathrm{T}}=0.109\right)$, but a low proportion of the total allelic variance is attributed to variation among subspecies/islands $\left(H_{\mathrm{b}}=0.035\right.$, hierarchical AMOVA: $3.77 \%$ of total variance). The endemic bee (Xylocopa darwinii) accounted for $87.30 \%$ of the floral visits to G. leucantha.

Main conclusions We inferred a single origin for an insular lineage that colonized the Galápagos Islands from northern Peru in the Pleistocene. Recent colonization of the archipelago, Pleistocene land bridges between islands and active gene flow promoted by $X$. darwinii may account for the low-moderate genetic differentiation of $G$. leucantha subspecies. An unusual pollination shift from ornithophily (hummingbirds on the continent) to entomophily (Xylocopa in the Galápagos Islands) is supported.

\section{Keywords}

genetic diversity, geographical speciation, island colonization, ornithophily, pollination network, secondary melittophily.
Correspondence: Pablo Vargas, Department Botánico - CSIC, Plaza de Murillo 2, 28014 Madrid, Spain.

E-mail: vargas@rjb.csic.es 


\section{INTRODUCTION}

The Galápagos Islands were formed by the emerging tops of submarine volcanoes rising from the sea floor and currently forming 13 large islands and about 100 small islets. Located on the equator, the Galápagos Islands (hereafter Galápagos) are known worldwide for their highly diverse forms of life, rich ecosystems and their unique geological composition (Gillespie \& Clague, 2009). Unfortunately, insular endemic plants are vulnerable to extinction in the Galápagos due to the direct negative impact of humans, habitat degradation, competition and hybridization with alien species (Rieseberg \& Swensen, 1996; Maunder et al., 1998). Nearly one-fifth of the endemic plant species are Endangered and c. 12\% are Critically Endangered (www.galapagos.org/conservation/conse rvation). The Galápagos shrub snapdragon, Galvezia leucantha, is one of such species included in the red list of the endemic plants of Ecuador as Endangered (León-Yánez et al., 2011) probably as a consequence of intense goat herbivory in the past (Tye \& Jäger, 2000). A conservation programme helped to protect the Galvezia populations of Santiago and
Rábida islands (Atkinson et al., 2008), on which goats were exterminated in 2000, but herbivory by feral livestock is still a major threat on the larger islands (Carrión et al., 2011).

Although the Galápagos shrub snapdragon has been recognized since its original description, the continental species of Galvezia has been subject to scientific discussion (Dillon \& Quipuscoa, 2014). A new taxonomic account proposes that Galvezia Dombey ex Juss. (Antirrhineae, Plantaginaceae) is a small-sized genus of four perennial shrub species distributed in arid habitats near the Pacific coast of Peru and Ecuador (G. elisensii, G. fruticosa, G. grandiflora) and the Galápagos (G. leucantha) (Elisens, 1989; Dillon \& Quipuscoa, 2014). Mainland species of Galvezia are morphologically similar (Fig. 1a-d), with differences typically confined to corolla size, anther filament pubescence and leaf shape (Sutton, 1988). In addition, the Galápagos shrub snapdragon has several unique morphological characters (Wiggins, 1968) (Fig. 1e-g), whereas Ecuadorian and Peruvian species have red flowers with long corolla tubes, G. leucantha has shorter and wider corollas and spans a broad colour range (whitishto-purple) (Fig. 1). Galvezia leucantha exhibits
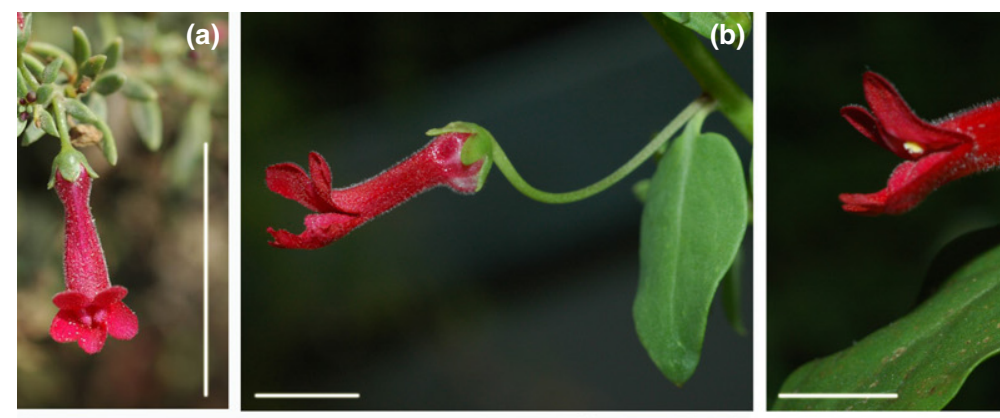

(e)
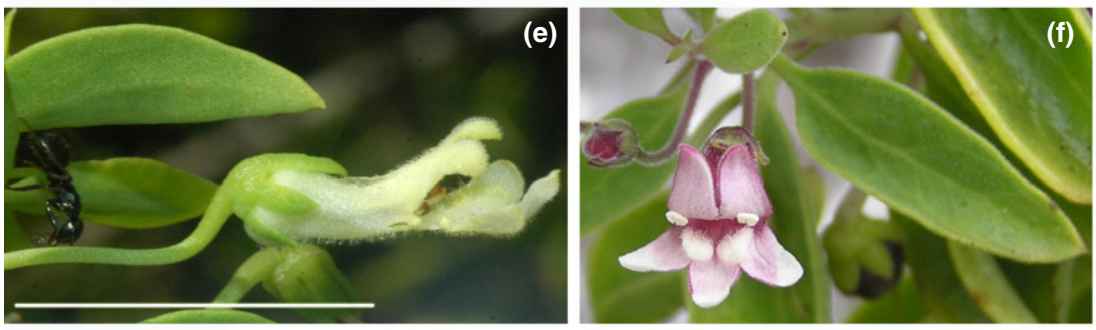

(f)
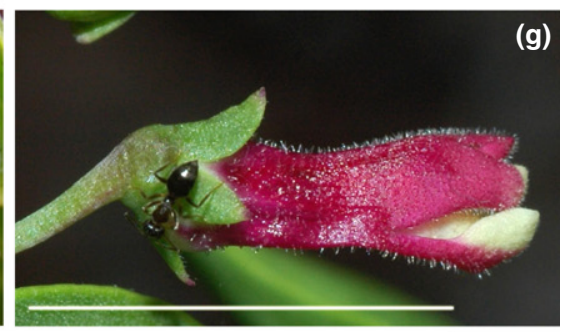

(h)
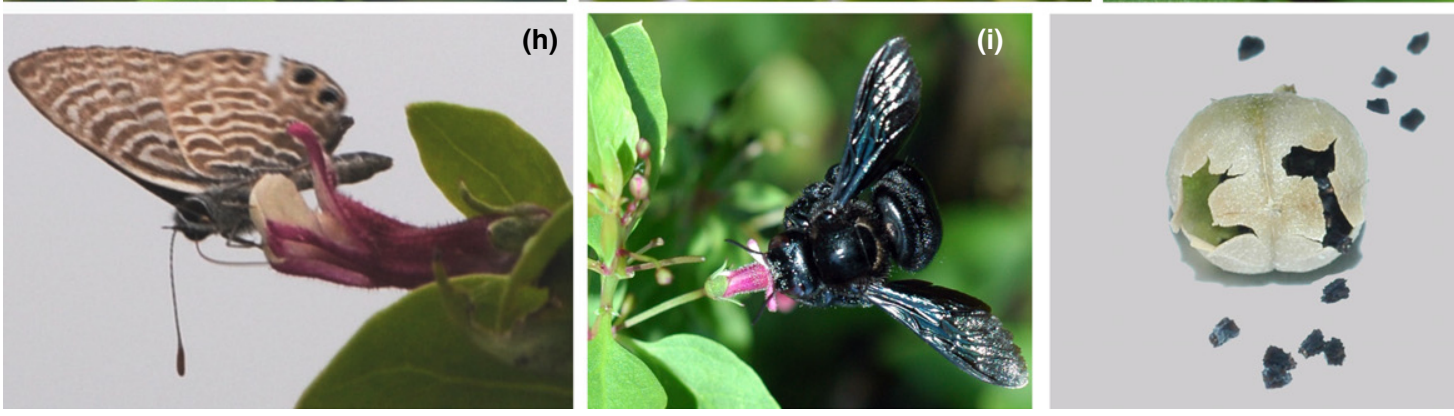

Figure 1 Floral diversity of Galvezia species. G. elisensii (a), G. fruticosa (b), G. grandiflora (c \& d), G. leucantha subsp. leucantha (e), G. leucantha subsp. pubescens (f), G. leucantha subsp. porphyrantha (g), Leptotes parrhasioides foraging in G. leucantha subsp. porphyrantha from population SAJam (h), Xylocopa darwini foraging in G. leucantha subsp. porphyrantha from population SAJam (i), open capsule (j). The scale bars correspond to $1 \mathrm{~cm}$. Photographs by M.O. Dillon (a), P. Vargas (b-e, g, i, j), W. Simbaña (f), A. Traveset (h). [Colour figure can be viewed at wileyonlinelibrary.com] 
morphological variation leading to the historical recognition of three subspecies (Wiggins, 1968; Wiggins \& Porter, 1971; Tye \& Jäger, 2000). Subspecific taxa within this species are delimited by young branches, pedicels and calyx pubescence between subspp. pubescens and leucantha/porphyrantha, while corolla colour delimits subspp. leucantha and porphyranta (Fig. 1e-g). All subspecies are geographically restricted to cliffs, lava flows and old craters of the four westernmost islands (Fig. 2): subsp. leucantha occurs on Isabela and Fernandina; subsp. pubescens is endemic to Rábida Island; and subsp. porphyrantha has only a few populations scattered on Santiago Island.

Genetic diversity is essential for reconstruction of the evolutionary history of the species and conservation programmes. However, studies on plant genetic diversity of Galápagos plants are extremely scarce (but see Jaramillo \& Atkinson, 2011). In particular, former studies based on allozyme/isozyme variation of Galvezia found genetic links and minimal variation between Galápagos populations, which suggested a genetic bottleneck that prevented description of inter- and intra-island movements and population differentiation after a single colonization event of Galvezia arriving in the Galápagos (Elisens, 1992). Most of the Galápagos flora has long been assigned to the Americas (Hooker, 1847). Indeed, floristic (Wiggins \& Porter, 1971) and phylogenetic (e.g. Moore et al., 2006; Trusty et al., 2012) studies have shown that most species of the Galápagos originated from South America and the Caribbean. Galvezia fruits are dehiscent capsules (Dillon \& Quipuscoa, 2014) (Fig. 1j). Both fruits and seeds lack structures that favour long-distance dispersal, which leads to interpreting a single colonization event (Elisens, 1985; Vargas et al., 2012). Nevertheless, a high number of early colonists appear to have arrived in the Galápagos irrespective of their diaspore

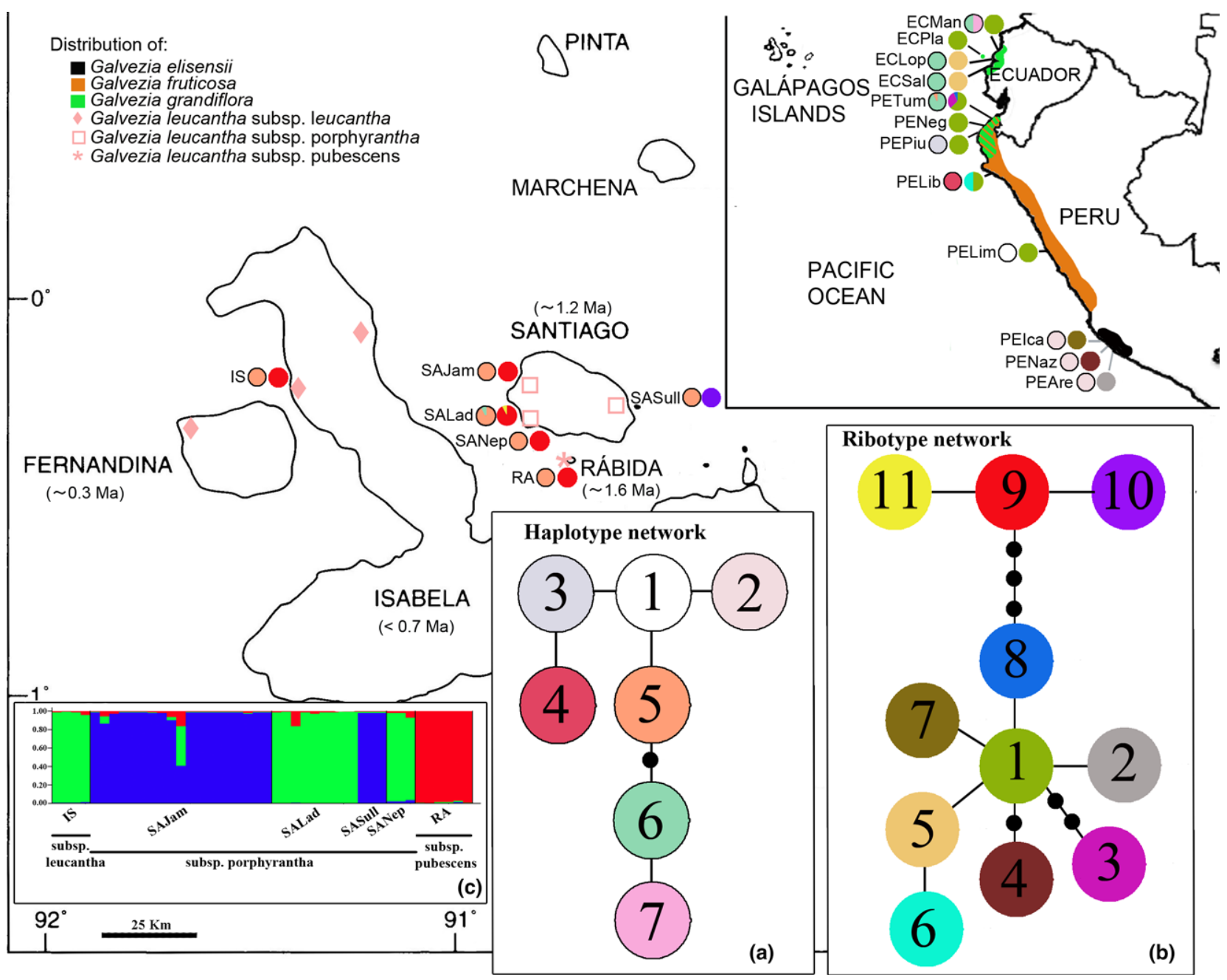

Figure 2 Distribution map and geographical range of seven haplotypes and 11 ribotypes of six Galvezia taxa from Peru, continental Ecuador and the Galápagos Islands. Statistical parsimony network based on (a) ndhF-rpL32 and (b) ITS sequences of Galvezia taxa. STRUCTURE results for Galvezia leucantha $(n=52)$ using 194 AFLP markers and $K=3$ population clusters (c). Haplotypes (1-7) and ribotypes (1-11) are indicated by numbers, lines indicate a single nucleotide substitution, and dots ( represent extinct or not detected haplotypes/ribotypes. [Colour figure can be viewed at wileyonlinelibrary.com] 
dispersal syndromes (Vargas et al., 2012). Both single and multiple independent colonization events have historically been proposed, based simply on taxonomy (Wiggins \& Porter, 1971). Indeed, several lineages sampled at the species (Darwinothamus, Andrus et al., 2009) and population (Croton scouleri, Rumeu et al., 2016) levels indicate that multiple colonization events may have occurred in spite of the isolation of the archipelago (c. $1000 \mathrm{~km}$ off the coast of Ecuador). Although a genetic link between G. leucantha (Galápagos) and South America (G. fruticosa) has already been proposed based on allozymes (Elisens, 1992), lack of accurate molecular markers, such as those from DNA, hindered more detailed inferences about the spatio-temporal history of Galvezia in the Galápagos.

Community-based conservation strategy is necessary to protect endangered plants because pollinators are essential for the reproductive success of the plants. A decrease in availability of pollinators may lead to a suppression of outcrossing and a decrease in genetic variability. Elisens (1992) suggested that red flowers with narrow corolla tubes would be adaptations for pollination by hummingbirds in mainland species. Shorter and wider whitish-to-purple corollas are pollinated by carpenter bees (Xylocopa darwini) in the Galápagos species. However, the pollinator fauna is still poorly documented for the entire genus. Over 65 families of angiosperms display ornithophilous floral traits (Cronk \& Ojeda, 2008); that is, they offer numerous cases of recurrent convergent evolution involving certain flower features (tubular flowers, red corollas, flower orientation, among others) related to pollination by birds. This co-evolutionary association is well known in the Americas, where historical presence of hummingbirds is related to pollination shifts primarily derived from insect (entomophily) to bird (ornithophily) pollination (Rauscher, 2008). The loss of bird pollination seems to be a rare evolutionary pattern (Wilson et al., 2007; Rauscher, 2008). In the Galápagos, the role of birds as pollinators has been historically underestimated given the absence of specialized nectarivorous birds (Traveset et al., 2015a,b).

Our working hypothesis is that a single introduction to the Galápagos occurred in the lower Pleistocene, most probably from northern coastal Peru (Elisens, 1989), followed by changes in floral traits related to bee-pollination. In this study, we performed phylogenetic and phylogeographic analyses using nuclear (ITS sequences, AFLPs) and plastid ( $n d h F$ and $n d h F-r p L 32$ sequences) DNA variation from the four species and three subspecies of Galvezia to: (1) test the monophyly of the Galápagos populations; (2) find out the sister group of G. leucantha; (3) pinpoint a source area from the continent linked to Galápagos populations; (4) determine population structure of G. leucantha across the Galápagos; and (5) characterize their reproductive biology, floral visitors and pollination communities to help understand the evolutionary history of Galvezia lineages. The ultimate goal is to consider the evolutionary process of Galvezia differentiation in conservation planning of the Galápagos shrub snapdragon.

\section{METHODS}

\section{Sampling strategy and DNA sequencing}

Leaf samples were collected from 18 populations (87 individuals) of Galvezia species across Peru (10 populations/30 individuals), continental Ecuador (4/5) and the Galápagos (6/52) (Fig. 2, Table 1). Between 1 and 21 individuals per population were sampled depending on population abundance (Table S1 in Appendix S1 in Supporting Information). All known populations of the three subspecies of G. leucantha were sampled, except for subsp. leucantha from Fernandina, where three expeditions $(2008,2010,2014)$ failed to find the population suggested by a herbarium specimen deposited in the CDF herbarium (Cabo Douglas, leg. T. Luong), and from eastern Isabela, where we also failed in 2014 (Volcán Alcedo, leg. T. Luong). Total genomic DNA was extracted from dried leaves using the Dneasy Plant Mini Kit (Qiagen, California) according to the manufacturer's instructions. A pilot study was performed to search for the most variable nuclear (AGT1, AroB, ATI03, EIF3E, ITS) and plastid (atpI-atpH, matk, ndhF, ndhF-rpL32, psbC-trnS, trnD-trnT, trnDguc, trnH-trnK, trnS-trnfM, trnS-trnG, trnT-L-F) DNA sequences within Galvezia (Table S2). The pilot study revealed the sequences of the nuclear ribosomal ITS region and the plastid intergenic spacer ndhF-rpL32 to be the most variable (Table S2). Therefore, the ITS (84 Galvezia samples) and the ndhF-rpL32 (83 Galvezia samples) regions were sequenced.

In addition, to infer phylogenetic relationships within Antirrhineae, two data sets were built based on previously published data plus newly generated sequences (Table S1). The nuclear ribosomal ITS (32 newly generated Antirrhineae sequences) and the plastid $n d h F$ gene sequences (34 newly generated Antirrhineae sequences) helped infer phylogenetic relationships among 166 and 163 Antirrhineae taxa, respectively. In addition, phylogeographic patterns were inferred using ITS (87) and ndhF-rpL32 (83) newly generated sequences of six Galvezia taxa. Methods for DNA extractions, PCR amplifications and sequencing were described in two recent studies of Antirrhineae for ITS (Fernández-Mazuecos et al., 2013) and $n d h \mathrm{~F}$ (Vargas et al., 2014). See Appendix S2 for $n d h F-r p L 32$ sequencing details and for clarification of three incongruent results identified in previous Antirrhineae phylogenies (Ghebrehiwet et al., 2000; Vargas et al., 2004) according to Guzmán et al. (2015a).

\section{Molecular dating}

The nuclear ITS and the plastid $n d h F$ gene were analysed to estimate divergence times of Galvezia and related lineages. The analysis was implemented in BEAST v.1.8.2 (Drummond \& Rambaut, 2007) on the CIPRES portal teragrid (www.phylo.org; Miller et al., 2010). We used a birth-death model for the tree prior, an uncorrelated relaxed molecular clock, a random starting tree, and the models selected by jModelTest (Posada, 2008) for each DNA region (ITS: 
Table 1 Accession data, haplotype and ribotype number of 18 populations of Galvezia taxa (87 individuals). Taxonomy follows that of Dillon \& Quipuscoa (2014).

\begin{tabular}{|c|c|c|c|c|c|}
\hline $\begin{array}{l}\text { Population } \\
\text { code }\end{array}$ & Taxon & Locality (number of individuals) & Voucher number & $\begin{array}{l}\text { Haplotype } \\
\text { number }\end{array}$ & $\begin{array}{l}\text { Ribotype } \\
\text { number }\end{array}$ \\
\hline PEAre & G. elisensii & Peru, Arequipa (1) & F1940835 & 2 & 2 \\
\hline PENaz & G. elisensii & Peru, Nazca (1) & F2144517 & 2 & 4 \\
\hline PEIca & G. elisensii & Peru, Departamento Ica (1) & F2184045 & 2 & 7 \\
\hline PELib & G. fruticosa & Peru, La Libertad, San Pedro de Lloc (2) & WE825 (OKL) & 4 & 1,6 \\
\hline PELim & G. fruticosa & Peru, Lima, Valle del río Chillon (5) & MA763175 & 1 & 1 \\
\hline PEPiu & G. grandiflora & Peru, Departamento Piura (2) & WE828 (OKL) & 3 & 1 \\
\hline PETum & G. grandiflora & Peru, Tumbes (16) & MA763174 & 5,6 & $1,3,8$ \\
\hline PENeg & G. grandiflora & Peru, Negritos (2) & MA763173 & - & 1 \\
\hline ECMan & G. grandiflora & Ecuador, Manabí, Manta (2) & WS610/WS619 (MA) & 6,7 & 1 \\
\hline ECSal & G. grandiflora & Ecuador, Manabí, Salango (1) & WS612 (MA) & 6 & 5 \\
\hline ECPla & G. grandiflora & Ecuador, Manabí, Plata Island (1) & WS613 (MA) & 6 & 1 \\
\hline ECLop & G. grandiflora & Ecuador, Manabí, Puerto López (1) & WS615 (MA) & 6 & 5 \\
\hline IS & $\begin{array}{l}\text { G. leucantha subsp. } \\
\text { leucantha }\end{array}$ & $\begin{array}{l}\text { Ecuador, Galápagos Islands, Isabela, } \\
\text { Tortuga Negra (6) }\end{array}$ & $\begin{array}{l}33 / 35 / 37 / 39 / 41 \mathrm{BGA} 14 \\
+130 \mathrm{PV} 08\end{array}$ & 5 & 9 \\
\hline SANep & $\begin{array}{l}\text { G. leucantha subsp. } \\
\text { porphyrantha }\end{array}$ & $\begin{array}{l}\text { Ecuador, Galápagos Islands, Santiago, Cabo } \\
\text { Nepean (3) }\end{array}$ & 11100 CDRS & 5 & 9 \\
\hline SASull & $\begin{array}{l}\text { G. leucantha subsp. } \\
\text { porphyrantha }\end{array}$ & $\begin{array}{l}\text { Ecuador, Galápagos Islands, Santiago, } \\
\text { Bahía Sullivan (3) }\end{array}$ & 11874 CDRS & 5 & 10 \\
\hline SALad & $\begin{array}{l}\text { G. leucantha subsp. } \\
\text { porphyrantha }\end{array}$ & $\begin{array}{l}\text { Ecuador, Galápagos Islands, Santiago, } \\
\text { Bahía Ladilla (13) }\end{array}$ & $\begin{array}{l}\text { 29PV10/41-45PV14/47PV14 } \\
\text { (MA) }\end{array}$ & 5,6 & 9,11 \\
\hline SAJam & $\begin{array}{l}\text { G. leucantha subsp. } \\
\text { porphyrantha }\end{array}$ & $\begin{array}{l}\text { Ecuador, Galápagos Islands, Santiago, } \\
\text { Bahía James (21) }\end{array}$ & 27PV10 (MA) & 5 & 9 \\
\hline RA & $\begin{array}{l}\text { G. leucantha subsp. } \\
\text { pubescens }\end{array}$ & Ecuador, Galápagos Islands, Rábida (6) & $17871 \mathrm{CDRS} / 17872 \mathrm{CDRS}$ & 5 & 9 \\
\hline
\end{tabular}

$\mathrm{GTR}+\mathrm{G}$, ndhF: $\mathrm{GTR}+\mathrm{I}+\mathrm{G})$. We did two independent runs; each one for 120 million steps sampled every 12,000th. Convergence to stationarity and effective sample size (ESS) of model parameters were assessed using TRACER 1.5 (Rambaut \& Drummond, 2007). Samples from both independent runs were pooled after removing a $10 \%$ burn-in using Log Combiner 1.8 (Drummond \& Rambaut, 2007). We used a previous molecular-estimated crown group age of Antirrhineae as a calibration point (Vargas et al., 2014) and applied a normally distributed calibration point prior with a mean of $30.22 \pm 4(\mathrm{SD})$ million years $(\mathrm{Ma})$.

\section{Phylogeographic data analysis}

A cpDNA (ndhF-rpL32) and a nDNA (ITS) sequence network were constructed using the software TCS 1.21 (Clement et al., 2000), which implements a statistical parsimony approach using the algorithm described in Templeton et al. (1992). The maximum number of differences among sequences, as a result of single substitutions, was calculated with $95 \%$ confidence limits and treating gaps as missing data.

\section{AFLP fingerprinting of G. leucantha and data analysis}

An AFLP approach (see for details Guzman et al., 2015b) was used to find out genetic variability and structure across
G. leucantha accessions. Primer sequences for AFLPs are shown in Table S3. Initially, 32 selective primer combinations were analysed in a subset of five samples comprising the three subspecies of G. leucantha. One replicate was included to test for reproducibility.

AFLPs profiles were analysed using GENEMAPPER 4.1 software (Applied Biosystems, Foster City, CA, USA). Six primer combinations (EcoRI-ACC/MseI-CTT, EcoRI-AGA/MseICAC, EcoRI-AAC/MseI-CAA, EcoRI-ACC/MseI-CAC, EcoRIACC/MseI-CAT and EcoRI-AAC/MseI-CAC) were chosen based on the number of polymorphic markers and the level of reproducibility. Markers $<100$ bp in length were removed from the data as these showed some evidence of size homoplasy using the method of Vekemans et al. (2002), implemented in the software AFLP-SURV 1.0 (distributed by the author. Laboratoire de Génétique et d'Ecologie Végétales. Université Libre de Bruxelles. Belgium). All ambiguous markers and singletons were excluded from the data set prior to analyses. See Appendix S2 for a full description of genetic diversity and structure analyses.

\section{Autogamy test}

We carried out autogamy experiments in two species of Galvezia to test whether self-fertilization occurs in the genus. The experiment was performed on the individuals cultivated in the glasshouse of the Real Jardín Botánico in Madrid: 
seven individuals of G. grandiflora (four from Tumbes (PETum) and three from Negritos (PENeg), Fig. 2) and one individual of G. fruticosa (from Lima, PELim). Between 2 and 309 flowers per individual (mean $=84.33$ ) were examined. As the glasshouse was closed, we did not bag flower buds, but marked 1000 flowers of G. grandiflora and 12 of G. fruticosa. At the end of the experiment, we checked whether fruit developed from marked flowers. Variation in fruit set between (1) two populations of G. grandiflora (PETum and PENeg) and (2) two species of Galvezia (G. fruticosa and G. grandiflora) was analysed. A nonparametric k-sample median test was performed with IBM sPSS Statistics v. 21.

\section{Floral visitors}

One population of G. grandiflora [Isla de la Plata, continental Ecuador, February 2011; see also Guzmán et al. (2015a)] and two populations of G. leucantha (subspp. leucantha, Isabela Island, February 2011 and May 2014; and subspp. porphyrantha, Santiago Island, February 2011) displaying different numbers of individuals and flowers were chosen for floral visitor surveys. All surveys were performed during the flowering peak by direct observation of flowers at Galvezia locations (for 15-min intervals, followed by 5 -min pauses). Diurnal and nocturnal surveys were performed on all populations for a total of $400 \mathrm{~min}$ (Table S4), reaching a maximum time of $240 \mathrm{~min}$ for Isabela and a minimum time of 75 min for Santiago. During the surveys, the identities of all insect visitors making contact with the reproductive organs of the flowers were recorded (Vargas et al., 2010). One specimen per species was captured for identification and deposited at the insect collection at the Charles Darwin Research Station, Puerto Ayora (Santa Cruz Island).

\section{Pollination network analysis}

To characterize floral visitors to G. leucantha and to evaluate how the structure of pollination interactions of this species differs from that of other coexisting plant species, we assembled a community-level pollination network based on flower visitation censuses. The pollination network was constructed in the arid zone of Bahía James (Santiago) encompassing the coastal community of Santiago described in Traveset et al. (2013) and the nearby community of G. leucantha subsp. porphyrantha present on a rocky outcrop c. $1 \mathrm{~km}$ away. Flower visitors were quantified by performing timed censuses $(125 \mathrm{~h})$ on all flowering species on both sites during the peak of the flowering season (February) in 2010 and 2011. All animals contacting the reproductive organs of the flowers within the observation period were identified, and the interactions compiled on a large quantitative interaction matrix (Traveset et al., 2013). The pollination network was visualized using the 'bipartite' package (Dormann et al., 2009) for R (R Core Team, 2015), and three key descriptors of species interactions patterns were calculated, namely plant linkage level, that is number of flower visitor species per plant; plant specialization index $d_{p}^{\prime}$ measuring the selectiveness of each species as the deviation from a visitation pattern based exclusively on visitor abundance (Blüthgen et al., 2006); and plant strength, quantifying the importance of each plant species to the pollinator community (Bascompte et al., 2006).

\section{RESULTS}

\section{Phylogenetic relationships and divergence times}

A chronogram based on posterior means from MCMC tree of both ITS and $n d h \mathrm{~F}$ sequences is shown in Fig. S1 (Antirrhineae) and Fig. 3 (Galvezia-Pseudorontium). Our wellsupported results indicated (1) monophyly of Galvezia species and populations of each of the four species (1.00 PP), except for a sample of G. fruticosa; (2) the genus Galvezia diverged from Pseudorontium primarily during the MiocenePliocene (8.88-2.28 Ma, median 5.11 Ma, 95\% HPD). Each analysis revealed one lineage of G. fruticosa plus G. elisensii populations as sister to the G. leucantha lineage (Fig. 3), but with low support. Monophyly is also inferred for G. leucantha populations with high support values (1.00 PP). Differentiation of Galápagos populations occurred in the MiddleUpper Pleistocene (0.66-0.09 Ma, median 0.30 Ma, 95\% HPD).

\section{Phylogeographic data analysis}

The $n d h F-r p L 32$ sequences varied in seven nucleotide-substitution haplotypes within Galvezia (Table 1, Table S5). There were no haplotypes exclusive to the Galápagos (Fig. 2). Haplotype 5 was distributed in six Galápagos populations and one population from Peru (38.88\% of all populations), whereas haplotype 6 was found in five populations from Peru, continental Ecuador and Galápagos (31.25\% of all populations; Table 1) (Fig. 2). Four (1, 3, 4 and 7) of the seven haplotypes were each found exclusively in a single population of the continent. At the species level, the same haplotype was detected in all populations within each species, except for three haplotypes found exclusively in each of the three populations of G. fruticosa (Table 1; Fig. 2). A geographical pattern of haplotype distribution is observed because three haplotypes (5, 6 and 7) are exclusively found in the northern distribution ( $G$. grandiflora), while one haplotype (1) is the only one found in the southern distribution (G. elisensii) of the continental Galvezia. Haplotype 5 was shared by all subspecies of G. leucantha (Table 1), while haplotype 6 was found exclusively in one individual of G. leucantha subsp. porphyrantha. At the population level, the same haplotype was detected in all individuals within each population, except for two haplotypes in two populations of G. grandiflora (ECMan, PETum) and two in the population of G. leucantha subsp. porphyrantha SALad (Table 1; Fig. 2).

The ITS sequences distinguished 11 nucleotide-substitution ribotypes in Galvezia (Table 1, Table S6). Ribotype 1 was 


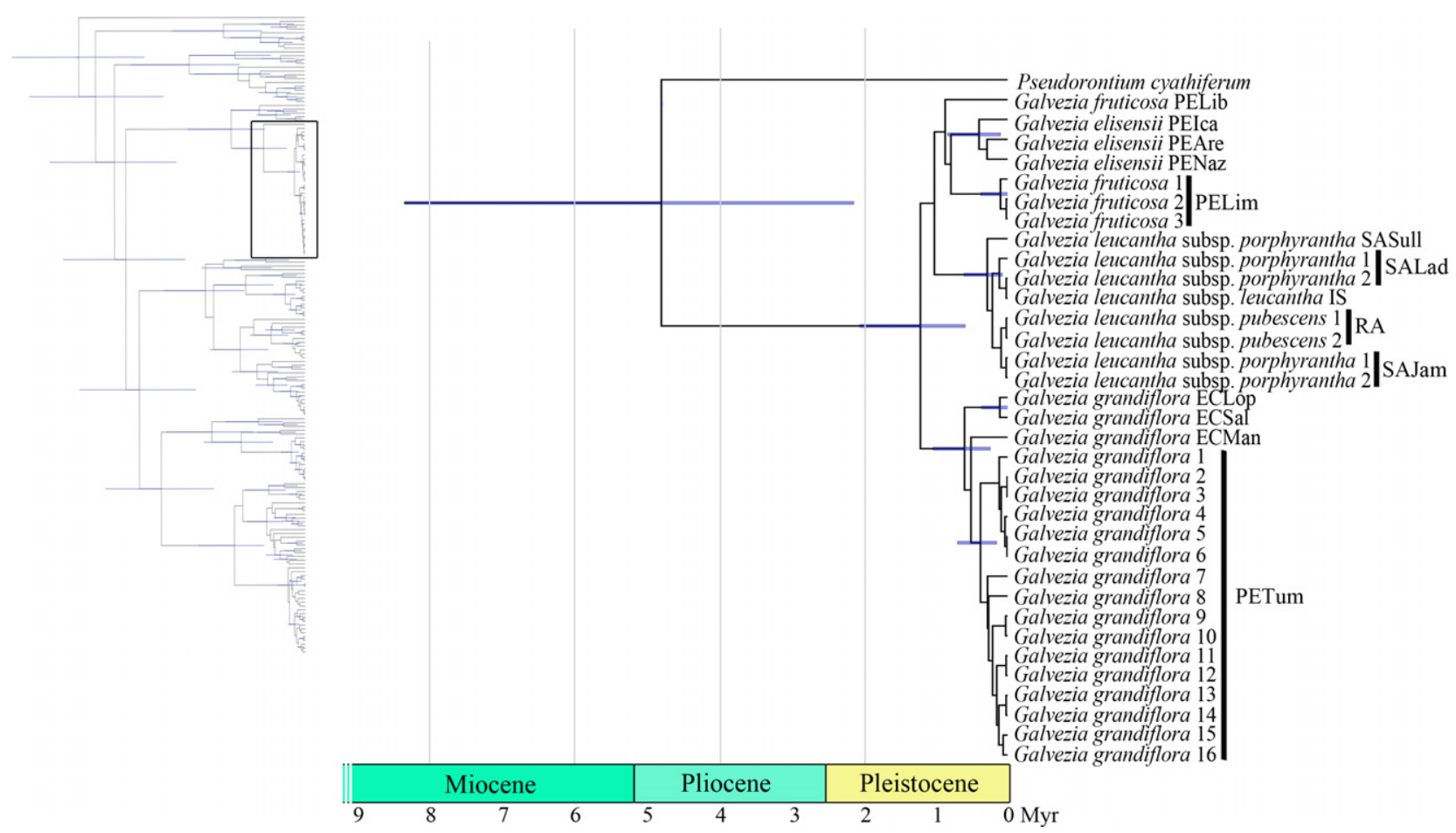

Figure 3 Detail of the Maximum Clade Credibility chronogram of the nuclear ribosomal ITS and the plastid $n d h F$ gene sequences inferred using BEAST to establish Galvezia lineages. Time scale in millions of years before present (Ma). Error bars (blue) represent 95\% posterior credibility intervals and are given only for nodes present on more than $95 \%$ of sampled trees. The whole MCC chronogram is shown in Fig. S1. [Colour figure can be viewed at wileyonlinelibrary.com]

widely distributed in seven populations from Peru and continental Ecuador (38.88\% of all populations; Table 1), whereas ribotype 9 was distributed exclusively in the five Galápagos populations (22.22\% of all populations) (Fig. 2). Eight of the 11 ribotypes $(2,3,4,6,7,8,10$ and 11) were each found exclusively in a single population. Ribotype 9 was shared over all subspecies of G. leucantha (Table 1), while ribotypes 10 and 11 were each found exclusively in one population of G. leucantha subsp. porphyrantha. At the population level, the same ribotype was detected in all the individuals within each population, except for two ribotypes in the population of G. fruticosa PELib, three in G. grandiflora (PETum) and two in G. leucantha subsp. porphyrantha SALad (Table 1; Fig. 2).

TCS constructed a single network of seven Galvezia haplotypes with no loops (Fig. 2a). Only two haplotypes (5 and 6) were found in the Galápagos, which were connected by a missing haplotype. Interestingly, these two haplotypes are also present in the continent. The network detected the interior haplotype 1 (continent) as the one with the highest number of mutational connections (three connections; Fig. 2a).

TCS constructed a single network of 11 Galvezia ribotypes with no loops. Continental ribotypes (1-8) were connected to Galápagos ribotypes by three absent (extinct or not found) ribotypes (Fig. 2b). Nevertheless, the continental ribotype 8 (only found in PETum) is the closest one to the
Galápagos lineage. The network detected the interior ribotype 1 (continent) as the one with the highest number of mutational connections (six connections; Fig. 2b). Ribotype 9 is also interior in the Galápagos lineage and widespread across G. leucantha accessions.

\section{AFLP genetic diversity in G. leucantha}

The pilot study for the selection of primer combinations yielded a percentage of polymorphic markers between 0 and $50 \%$. The reproducibility of the observed markers ranged between 66.60 and 100\% (Table S7). Six AFLP selective primer combinations (EcoRI-ACC/MseI-CTT, EcoRI-AGA/ MseI-CAC, EcoRI-AAC/MseI-CAA, EcoRI-ACC/MseI-CAC, EcoRI-ACC/MseI-CAT and EcoRI-AAC/MseI-CAC) resulted in 194 unambiguous fragments when extended to the successfully genotyped sample of 52 individuals (six populations). All these fragments were polymorphic. The reproducibility of the used AFLP fragments was above $94 \%$ for the six primer combinations (Table S7).

Table 2 summarizes the genetic diversity among six populations of G. leucantha. Individual populations had a mean polymorphic loci percentage of $20.17 \%$, ranging from $6 \%$ in population from Bahía Sullivan to $33 \%$ in population from Bahía Ladilla. Per-population Nei's gene diversity $(\mathrm{Hj})$ (= expected heterozygosity), under a model assuming no deviation from Hardy-Weinberg genotypic proportions, ranged 
Table 2 Genetic diversity within six populations of Galvezia leucantha based on AFLP (194 markers).

\begin{tabular}{|c|c|c|c|c|c|c|c|}
\hline & $N$ & NPL & $A^{*}$ & Ap* & PLP $1 \%^{\dagger}$ & $\mathrm{Hj}$ & DW \\
\hline \multicolumn{8}{|l|}{ Populations } \\
\hline IS & 6 & 19 & 1.03 & 0.05 & 3.87 & 0.08 & 117.80 \\
\hline SANep & 3 & 14 & 1.13 & 0.01 & 0.82 & 0.08 & 122.06 \\
\hline SASul & 3 & 6 & 1.01 & 0.01 & 0.82 & 0.04 & 107.43 \\
\hline SALad & 13 & 33 & 1.04 & 0.02 & 6.29 & 0.10 & 104.00 \\
\hline SAJam & 21 & 28 & 1.03 & 0.02 & 3.14 & 0.07 & 140.02 \\
\hline $\mathrm{RA}$ & 6 & 21 & 1.05 & 0.05 & 1.13 & 0.08 & 137.17 \\
\hline Mean (SD) & - & $20.17(9.66)$ & $1.05(0.04)$ & $0.03(0.02)$ & $2.68(2.19)$ & $0.07(0.02)$ & $121.41(14.88)$ \\
\hline \multicolumn{8}{|l|}{ Subspecies } \\
\hline leucantha & 6 & 19 & $1.05^{\mathrm{a}}$ & $0.05^{\mathrm{a}}$ & $3.87^{\mathrm{a}}$ & $0.08^{\mathrm{a}}$ & $117.80^{\mathrm{a}}$ \\
\hline porphyrantha & 40 & 40 & $1.03^{\mathrm{a}}$ & $0.02^{\mathrm{b}}$ & $0.73^{\mathrm{a}}$ & $0.10^{\mathrm{a}}$ & $120.55^{\mathrm{a}}$ \\
\hline pubescens & 6 & 21 & $1.05^{\mathrm{a}}$ & $0.05^{\mathrm{a}}$ & $1.13^{\mathrm{a}}$ & $0.08^{\mathrm{a}}$ & $137.51^{\mathrm{a}}$ \\
\hline
\end{tabular}

$N$, number of individuals; NPL, number of polymorphic loci; A, allelic richness; Ap, private allelic richness; PLP, percentage of polymorphic loci at $1 \%$ level; $\mathrm{Hj}$, Nei's gene diversity (= expected heterozygosity); DW, rarity index (expressed as ratio of means).

*A and Ap were calculated using HP-Rare (Kalinowski, 2005) with rarefaction to three samples per population and one population per subspecies.

$\nmid$ PLP calculated using AFLPDIV (Coart et al., 2005; Petit et al., 1998) with rarefaction to three and six when analysing populations and subspecies.

${ }^{a}$ Medians not significantly different from each other (nonparametric k-sample median test for A, Ap, DW and PLP, $P<0.05$ ).

${ }^{\mathrm{b}}$ Medians significantly different from each other (nonparametric k-sample median test for A, Ap, DW and PLP, $P<0.05$ ).

from $0.04 \%$ (Bahía Sullivan) to $0.10 \%$ (Bahía Ladilla), with an average of $0.07 \pm 0.02 \%$. The proportion of rare AFLP markers did not significantly differ between subspecies, and it was the highest in subspecies pubescens ( $\mathrm{DW}=137.51$ ) (Table 2).

\section{Population genetic structure and relationships within G. leucantha}

There was low to moderate genetic differentiation among the studied G. leucantha populations $\left(F_{\mathrm{ST}}=0.2965, \quad P<0.01\right.$; Table 3). Significant $F_{\mathrm{ST}}$ estimates suggested that the populations did not form a single panmictic unit and that there are significant genetic differences between some populations. This is despite the fact that the low-to-moderate value of the estimate proposes that the levels of differentiation are not very high.

The two-dimensional PCoA and the AFLP-based neighbour-joining tree revealed weak population differentiation and the absence of a clustering pattern either by subspecies (Fig. S2). The hierarchical AMOVA indicated that 'subspecies' was not a significant source of variability (Table 4) and that most of the variance was among individuals within populations (77.95\%) and among populations within subspecies $(18.28 \%)$. The largest the $\Delta K$ value the most probable the $K$ value of 3 (Fig. S3). At $K=3$, Galvezia leucantha subsp. pubescens is separated from subspp. leucantha and porphyrantha (Fig. 2c). The analysis also reveals admixture between subspp. leucantha and porphyrantha (Fig. 2c). Galvezia leucantha subsp. porphyrantha is a heterogeneous subspecies with two groups including one shared with subsp. leucantha (Fig. 2c).

\section{Autogamy test}

The three populations of G. grandiflora and G. fruticosa were found to be selfers (Table S8). A high variability in fruit set was found within individuals of G. grandiflora population PENeg (0-100\%, Table S8), whereas intrapopulation variability was lower in PETum (59.22-36.76\%, Table S8). The single individual of G. fruticosa showed c. $60 \%$ of selfing. No significant differences in fruit set were

Table 3 Genetic differentiation between populations based on 194 AFLP markers found in 52 individuals (six populations) of Galvezia leucantha of the Galapagos.

\begin{tabular}{llllrr}
\hline & $H_{\mathrm{T}}$ & $H_{\mathrm{W}}(\mathrm{SD})$ & $H_{\mathrm{b}}(\mathrm{SD})$ & $F_{\mathrm{ST}}$ & Lower 99\% $F_{\mathrm{ST}}$ \\
\hline All populations & 0.1092 & $0.0767(0.0084)$ & $0.0326(0.0025)$ & 0.2965 & -0.0373 \\
Among subspecies & 0.1235 & $0.0884(0.0065)$ & $0.0351(0.0000)$ & 0.2833 & -0.0477 \\
\hline
\end{tabular}

$\mathrm{H}_{\mathrm{T}}$, total gene diversity; Hw, average gene diversity within populations; $\mathrm{H}_{\mathrm{b}}$, average gene diversity between populations; $F_{\mathrm{ST}}$, Wright's fixation index, that is differentiation between populations; Lower $99 \% F_{\mathrm{ST}}$ and Upper $99 \% F_{\mathrm{ST}}$, critical values at $99 \%$ in the randomization distribution of $F_{\mathrm{ST}}$, assuming no genetic differentiation between populations, based on 10,000 random permutations. Standard deviations (SD) are shown in brackets. 
Table 4 Hierarchical AMOVA based upon AFLP variation surveyed in a total of six populations (52 individuals) of three subspecies of Galvezia leucantha (subspp. leucantha, porphyrantha and pubescens).

\begin{tabular}{lrrrrr}
\hline Source of variation & d.f. & \multicolumn{1}{c}{ SS } & Variance components & Total variance (\%) & $P$-value \\
\hline Among subspecies & 2 & 81.078 & 40.539 & 3.772 & 0.182 \\
Among populations within subspecies & 3 & 111.958 & 37.319 & 18.282 & 0.004 \\
Within populations & 51 & 591.985 & 12.869 & 77.946 & 0.001 \\
\hline
\end{tabular}

$P$-value estimates are based on 9999 permutations. d.f., degrees of freedom and SS, sum of squared deviations.

found among species (median $=53.38, \chi_{1}^{2}=1.14, P=0.28$ ) and among G. grandiflora populations (median $=53.38$, $\left.\chi_{2}^{2}=1.33, P=0.51\right)$.

\section{Floral visitors}

No visitors were observed during the 85-min survey of G. grandiflora in Isla de la Plata (but see Guzmán et al. 2015a for additional results). In contrast, G. leucantha showed a high number of visits by the Galápagos carpenter bee $X$. darwinii (187 visits in $315 \mathrm{~min} ; 87.26 \%$ of visits) (Table S4). Only three other species, two ants (Nylanderia sp. and Camponotus zonatus) and the endemic lycaenid butterfly (Leptotes parrhasioides), were additionally observed visiting the population of Santiago.

\section{Pollination network analysis}

Overall, $125 \mathrm{~h}$ of visitation census were performed in the whole community of Bahía James (Traveset et al., 2013), resulting in the observation of 2182 visits including 87 animal species and 32 plant species (Table S9, Fig. 4 and Fig. S4). Regarding diversity of pollination visits, G. leucantha showed a lower linkage level ( $G$. leucantha $=4$; community mean $=7.10, \min =1, \max =26$ ), lower specialization (G. leucantha $=0.39$; community mean $=0.53, \min =0.062$, $\max =0.97)$ and lower species strength $(G$. leucantha $=2.20$; community mean $=3.20, \min =0.003, \max =15.30)$ than the average for all plant species in its community. Nevertheless, none of these differences were significant, due to the high dispersal of the data (Fig. S5).

\section{DISCUSSION}

Multidisciplinary studies, addressing several key issues (taxonomy, phylogenetics, population genetics, reproductive biology, pollination ecology, threat assessments), are essential to reconstruct evolutionary processes and to support more useful management programs (Silva et al., 2015). The present study of G. leucantha is still a rare case in literature of a

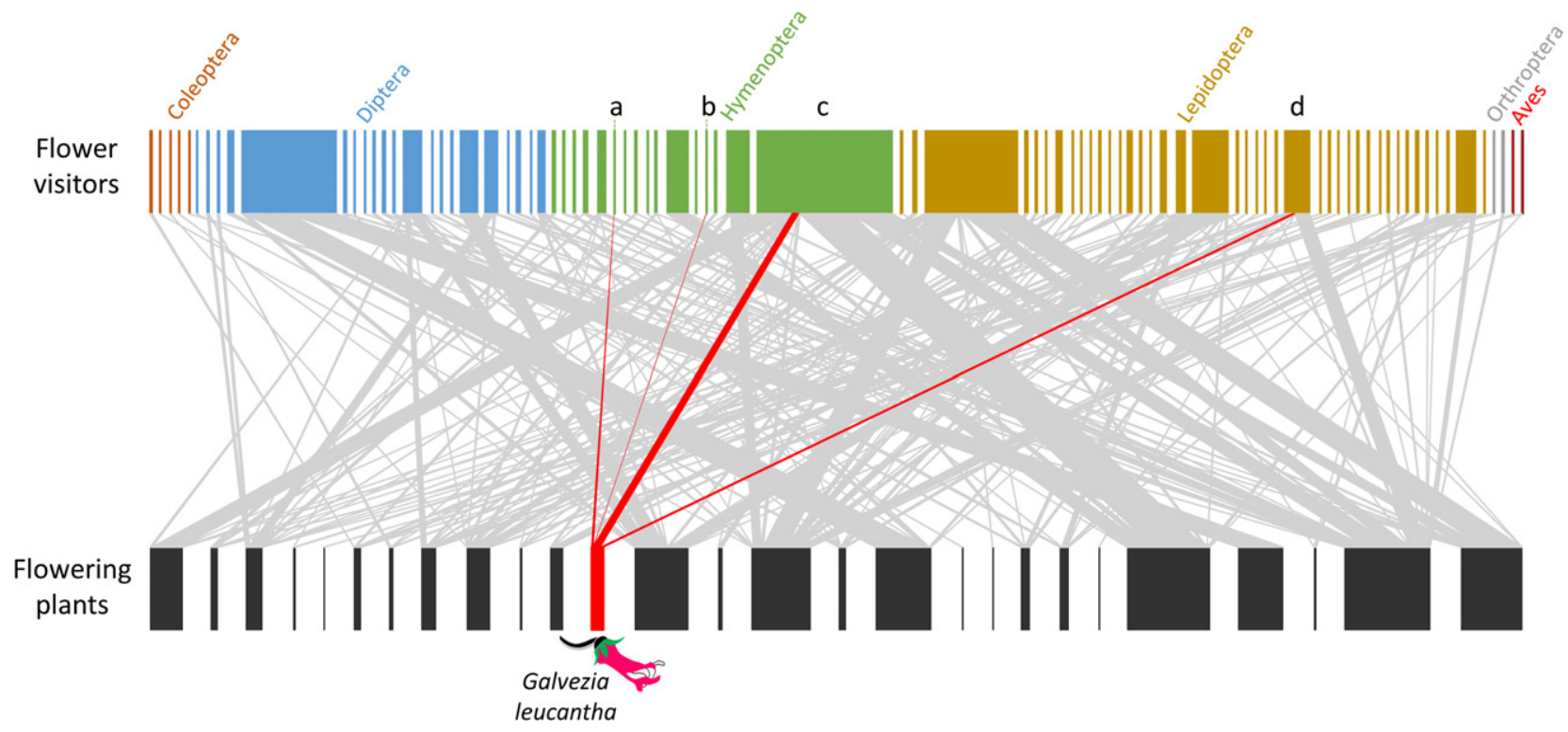

Figure 4 Pollination network of Bahía James (Santiago Island, Galápagos). This network quantifies the contacts between flower visitors (top level) with the reproductive organs of flowers (bottom level) in the community of Bahía James. A total of 7500 min of focal visitation census were performed in February 2010 and 2011, during which 2182 visits were recorded. The width of each box representing plants, animals and the interactions between the two is proportional to the number of visits observed. Colours represent different taxonomic groups of flower visitors. The four visitors to Galvezia leucantha, represented in red, are as follows: (a) Nylanderia sp., (b) Hymenoptera small black wasp, (c) Xylocopa darwini, (d) Leptotes parrhasioides (Table S4). [Colour figure can be viewed at wileyonlinelibrary.com] 
holistic conservation approach including evolutionary history of the species.

The origin of Galvezia may have occurred somewhere between the current distributions of Pseudorontium (SW North America) and Galvezia (NW South America) species in the Miocene $(<10 \mathrm{Ma})$. Rates of diversification in Galvezia are low (differentiation of four species during the Pleistocene) and distribution narrow (Fig. 2). Interestingly, one lineage found its way to colonize the remote Galápagos also during the Pleistocene.

\section{Geographical speciation}

Recent classification of Galvezia has included the Galápagos species (G. leucantha) together with four or three species, depending on circumscription of continental populations: G. fruticosa, G. ballii, G. lanceolata and G. sp. nov. (Elisens, 1992) or G. elisensii, G. fruticosa, G. grandiflora (Dillon \& Quipuscoa, 2014). Our phylogenetic results revealed that: (1) Galvezia is a well-defined genus within the Antirrhineae; (2) Galvezia and Pseudorontium are sister groups; and (3) the recognition of four Galvezia species is supported by primarily monophyletic groups of populations (Dillon \& Quipuscoa, 2014). The distribution of the continental species and haplotypes (and ribotypes at some extent) along the coast of Ecuador and Peru (Fig. 2) is congruent with a geographical pattern of latitudinal speciation during the Pleistocene. Specific geomorphic formations called lomas are common along the NW cost of South America, where a mild, uniform climate is characterized by regular formation of thick cloud banks below $1000 \mathrm{~m}$ during winter, as a result of the cold Humboldt sea current (Dillon et al., 2011). Similar lowland climate conditions are found on the Galápagos, involving lomas occupied by the Galápagos Galvezia. Taxonomic delimitation of G. leucantha is also congruent with a pattern of geographical isolation and speciation after a single colonization event of the Galápagos archipelago (Elisens, 1992).

\section{The colonization history of Galápagos by Galvezia}

The few phylogenies published for Galápagos plants suggest that continental ancestors may have colonized from many different areas including the Caribbean, Ecuador, Peru and Chile (Tye \& Francisco-Ortega, 2011; Trusty et al., 2012). Phylogeographic and phylogenetic analyses revealed a single, independent dispersal event by Galvezia from the mainland to the Galápagos archipelago (Figs 2 and 3). This result is consistent with the hypothesis proposed by Elisens (1992), who interpreted a single introduction to the Galápagos during the Pleistocene based on isozyme and chorological data. Phylogeography and genotype distribution of Galvezia suggested that the Peruvian population of Tumbes (PETum) was directly connected to the Galápagos lineage (Fig. 2). Interestingly, Tumbes is the closest continental area to Galápagos (c. $950 \mathrm{~km}$ ) and retains the highest diversity in terms of number of both haplotypes (two) and ribotypes (three) in a narrow area of Galvezia distribution. However, it is difficult to identify centres of dispersal for plants given the geographical and climatic changes resulting in potential waxing and waning processes during the Pleistocene (Cain, 1943). Moreover, our genotype networks of continental populations show a complex scenario of population relationships and geography (Fig. 2). Irrespective of whether Tumbes area is the cradle of the Galvezia ancestor that colonized Galápagos, it is indeed puzzling to understand how fruits or seeds with no traits related to long-distance dispersal (Fig. 1j) originally dispersed to Galápagos from any mainland area (but see Vargas et al., 2012). Nevertheless, some other plant traits, such as habitat similarity, the strong selfing pattern displayed in this genus (see high values for Tumbes population in Table S8), and the high germination rates of seeds obtained by selfing (B. Guzmán \& P. Vargas pers. obs.; Elisens, 1985) may have determined the successful colonization of Galápagos by Galvezia. Indeed, not only most of the Galápagos flora shows some level of autogamy and autonomous selfing (Chamorro et al., 2012) but also does other insular floras (New Zealand: Webb \& Kelly, 1993 and Juan Fernandez: Anderson et al., 2001; Bernardello et al., 2001).

The divergence time analysis of Galvezia lineages estimated a relatively recent colonization of the archipelago $(<600 \mathrm{kyr})$, followed by dispersal across four western islands. Some isolation of G. leucantha on these four western islands is reflected by some genetic differentiation of the populations and subtle flower traits currently used in subspecific taxonomy: leucantha on Isabela and Fernandina, pubescens on Rábida and porphyrantha on Santiago. However, our genetic analyses failed to find three well-defined lineages congruent with the three subspecies (Fig. 3; Fig. S1). Recent reconstruction of the archipelago's geodynamics based on sea level changes (eustasy) revealed that the four western-most islands have been recurrently connected by land bridges since $700 \mathrm{kyr}$ (Ali \& Aitchison, 2014). Both, land bridges and high interisland gene flow mediated by pollinators (X. darwinii; see Vargas et al., 2015), have likely been responsible for the poor geographical structure of the genetic variation observed in G. leucantha.

\section{Genetic variation and population demise in G. leucantha}

Total genetic diversity of G. leucantha is relatively high $\left(H_{\mathrm{T}}=0.11\right)$ (Table 2). One more endangered species (Calandrina galapagosa) in the Galápagos displays high genetic diversity (Jaramillo \& Atkinson, 2011). This pattern of high levels of genetic diversity in endemic and narrowly distributed plants is not exclusive of the Galápagos. Endemisms of the Canary Islands, for instance, also showed relatively high levels of average species-level total genetic diversity $\left(H_{\mathrm{T}}=0.19\right.$; Francisco-Ortega et al., 2000). Although genetic diversity of narrow endemics is higher for some insular species than expected from historical predictions, the causes of variation of genetic diversity on islands appear to be species specific (Fernández-Mazuecos et al., 2014). Care should be 
taken when comparing data between unrelated species as genetic diversity depends on numerous factors, namely life history, breeding system, growth life forms, geographical range and type of molecular method used (Powell et al., 1996; Nybom, 2004). The fact that genetic differentiation is relatively moderate in $G$. leucantha $\left(F_{\mathrm{ST}}=0.2965, P<0.01\right.$; Table 3), despite being narrowly distributed, is compatible with the distribution of extensive populations after speciation, followed by isolation and decline (Simbaña, 2007). In Galápagos, the most important factor causing population and species demise is human-mediated impacts, particularly goat herbivory and introduction of invasive plants (Cruz et al., 2009; Carrión et al., 2011). In the last decades, active conservation programmes undertaken by the Galápagos National Park Service succeeded in eradicating goats from several islands, including Santiago and Rábida (Carrión et al., 2011). Goats are still one of the main threats to endemic flora in larger islands, such as Isabela, where only two populations with extremely few individuals of the subsp. leucantha are known (Fig. 2) (Tye \& Jäger, 2000; Atkinson et al., 2008). One more endangered species (Calandrina galapagosa) displaying high genetic diversity is fastly recovering after the implementation of goat-proof fences in San Cristóbal (Jaramillo \& Atkinson, 2011).

\section{Loss of ornithophilous traits}

The scenario of recent colonization of the Galápagos archipelago from a northern Peruvian-southern Ecuadorian lineage of Galvezia was apparently accompanied by rapid differentiation in floral morphology (Fig. 1) and pollination biology. While there are some observations of hummingbirds visiting mainland Galvezia species with long, tubular, red flowers (Fig. 1a-d) (Guzmán et al., 2015a), the Galápagos shrub snapdragon shows paler, shorter flowers (Fig. 1e-g) that are primarily pollinated by the endemic carpenter bee (X. darwini; Table S4; Elisens, 1989, 1992). A shift in pollinator system from bird to bee-pollination is scientifically perceived as a rare pattern (Wilson et al., 2007; Rauscher, 2008); however, the Galápagos endemic G. leucantha offers an interesting case of secondary entomophily (melittophily). Given that a split between continental and Galápagos lineages of Galvezia occurred recently (Fig. 3), our phylogenetic results do not help reconstruct the ancestral condition of this evolutionary change. Nevertheless, the reconstruction of ancestral flower phenotypes of the Antirrhineae suggests that the most common recent ancestor of Galvezia-Pseudorontium had partially occluded corollas, which are related to bird pollination (Guzmán et al., 2015a).

Our pollinator survey additionally shows that G. leucantha is an entomophilous species that has insects of three groups (ants, bees, butterflies) as flower visitors. Particularly, the carpenter bee (X. darwinii) is primarily mediating pollen transfer between flowers of this plant species, and it is actually the most generalist species (pollinator hub) of the entire Galápagos flora (Traveset et al., 2013). Our surveys agree with preliminary observations and expectations for a strong bee-flower interaction (Elisens, 1989), although additional visitors have been observed (Table S4). Low insect specialization is interpreted when comparing results of G. leucantha to those from the other co-occurring plants of Bahía James (Santiago Island).

Despite the greater effort being dedicated to observing flower visitors on the Galápagos shrub snapdragon (630 $\mathrm{min}$ ) compared to the other plant species in the community (240 $\mathrm{min})$, G. leucantha flowers were never visited by birds, unlike those of two plant species (Acacia rurodiana and Lantana peduncularis) at Bahía James visited by two Galápagos finches (Geospiza fuliginosa and Camarrhynchus parvulus, Fig. 4 and Table S4). The role of birds as pollinators in the Galápagos has been historically underestimated given the absence of specialized nectarivorous birds. Indeed, estimation of pollen harvesting through inspection of pollen load on birds' beaks revealed at least 19 bird species visiting plants in Galápagos lowland communities (Traveset et al., 2015a,b). Although this interesting phenomenon (coined 'interaction release') appears to be generalized in the Galápagos (including Bahía James), no pollination attributable to birds seems to have occurred in the insular Galvezia lineage (see Traveset et al., 2015a,b). Indeed, birds were spotted perching on G. leucantha branches but never observed visiting its flowers (P. Vargas pers. obs.). Further evidence that $G$. leucantha is not visited by birds comes from the high number of pollen grains (over 1000 per sampled bird) identified from 17 plant species in Traveset et al. (2015a,b), of which none belonged to Galvezia.

\section{CONCLUDING REMARKS}

Conservation of endangered species has become a global concern in nature management, which requires the collation of information from different disciplines. In this study, we appraised results from taxonomy, genetics, phylogenetics, phylogeography and pollination ecology to reconstruct the evolutionary history of the Galápagos shrub snapdragon from a single colonization in the last 600.000 years. Causes for high morphological and genetic diversity include short island isolation in the past and long-range pollination primarily by a large and common bee (X. darwinii). Most recent population demise caused by goat hervibory over the last two centuries have contributed to its current conservation status. In addition, a rare case of evolutionary shift from bird- to beemediated pollination in Galvezia and Galápagos is hypothesized. Increasing field efforts to find new populations and to census and sample individuals from known populations, combined with ex situ conservation programs, will help prevent the extinction of the Galápagos shrub snapdragon.

\section{ACKNOWLEDGEMENTS}

The authors thank three anonymous reviewers for suggestions that improved the manuscript; M. Agudo, B. Fessl, H. 
Häger, P. Jaramillo, J.M. Olesen and J. Sánchez for field assistance; M.O. Dillon (G. elisensii) and W.J. Elisens (G. fruticosa) for plant material; E. Cano, A. Forrest, J. González and L. Sastre for laboratory assistance and both the Charles Darwin Foundation, the Direccion del Parque Nacional Machalilla and the Dirección del Parque Nacional Galápagos for essential logistics and research permit $\mathrm{N}^{\circ}$ 006/2008 PNG. This research was supported by the Spanish Ministry of Science and Innovation through funding conceded to PV (CGL2009-10031) and a Juan de la Cierva fellowship to BG.

\section{REFERENCES}

Ali, J.R. \& Aitchison, J.C. (2014) Exploring the combined role of eustasy and oceanic island thermal subsidence in shaping biodiversity on the Galápagos. Journal of Biogeography, 41, 1227-1241.

Anderson, G.J., Bernardello, G., Stuessy, T.F. \& Crawford, D.J. (2001) Breeding systems and pollination of selected plants endemic to Juan Fernández Islands. American Journal of Botany, 88, 220-233.

Andrus, N., Tye, A., Nesom, G., Bogler, D., Lewis, C., Noyes, R., Jaramillo, P. \& Francisco-Ortega, J. (2009) Phylogenetics of Darwiniothamnus (Asteraceae: Astereae) - molecular evidence for multiple origins in the endemic flora of the Galápagos Islands. Journal of Biogeography, 36, 1055-1069.

Atkinson, R., Rentería, J.L. \& Simbaña, W. (2008) The consequences of herbivore eradication on Santiago: are we in time to prevent ecosystem degradation gain? Galapagos Report, 2007-2008, 121-124.

Bascompte, J., Jordano, P. \& Olesen, J.M. (2006) Asymmetric coevolutionary networks facilitate biodiversity maintenance. Science, 312, 431-433.

Bernardello, G., Anderson, G.J., Stuessy, T.F. \& Crawford, D.J. (2001) A survey of floral traits, breeding systems, floral visitors, and pollination systems of the Angiosperms of the Juan Fernández Islands (Chile). The Botanical Review, 67, 255-285.

Blüthgen, N., Menzel, F. \& Blüthgen, N. (2006) Measuring specialization in species interaction networks. BMC Ecology, 6, 9, DOI: 10.1186/1472-6785-6-9.

Cain, S.A. (1943) Criteria for the indication of center of origin in plant geographical studies. Torreya, 43, 132-1545.

Carrión, V., Donlan, C.J., Campbell, K.J., Lavoie, C. \& Cruz, F. (2011) Archipelago-wide island restoration in the Galápagos Islands: reducing costs of invasive mammal eradication programs and reinvasion risk. PLoS ONE, 6, e18835.

Chamorro, S., Heleno, R., Olesen, J.M., McMullen, C.K. \& Traveset, A. (2012) Pollination patterns and plant breeding systems in the Galápagos: a review. Annals of Botany, 110, 1489-1501.

Clement, M., Posada, D. \& Crandall, K.A. (2000) TCS: a computer program to estimate gene genealogies. Molecular Ecology, 9, 1657-1659.

Coart, E., Van Glabeke, S., Petit, R., Van Bockstaele, E. \& Roldán-Ruiz, I. (2005) Range wide versus local patterns of genetic diversity in hornbeam (Carpinus betulus L.). Conservation Genetics, 6, 259-273.

Cronk, Q. \& Ojeda, I. (2008) Bird-pollinated flowers in an evolutionary and molecular context. Journal of Experimental Botany, 59, 715-727.

Cruz, F., Carrión, V., Campbell, K., Lavoie, C. \& Donlan, C.J. (2009) Bio-economics of large-scale eradication of feral goats from Santiago Island, Galápagos. Journal of Wildlife Management, 73, 191-200.

Dillon, M.O. \& Quipuscoa, V. (2014) Synopsis of Galvezia (Plantaginaceae: Antirrhineae), including a new cryptic species from southern Peru. Journal of the Botanical Research Institute of Texas, 8, 47-55.

Dillon, M.O., Leiva-González, S., Zapata-Cruz, M., LezamaAsencio, P. \& Quipuscoa-Silvestre, V. (2011) Floristic Checklist of the Peruvian Lomas formations - Catálogo florístico de las Lomas peruanas. Arnaldoa, 18, 7-32.

Dormann, C.F., Fründ, J., Blüthgen, N. \& Gruber, B. (2009) Indices, graphs and null models: analyzing bipartite ecological networks. Open Journal of Ecology, 2, 7-24.

Drummond, A.J. \& Rambaut, A. (2007) BEAST: Bayesian evolutionary analysis by sampling trees. BMC Evolutionary Biology, 7, 214.

Elisens, W.J. (1985) Monograph of the Maurandyinae (Scrophulariaceae-Antirrhineae). Systematic Botany Monographs, 5, 1-97.

Elisens, W.J. (1989) Genetic variation and evolution of the Galápagos shrub snapdragon. National Geographic Research, 5, 98-110.

Elisens, W.J. (1992) Genetic divergence in Galvezia (Scrophulariaceae): evolutionary and biogeographic relationships among South American and Galápagos species. American Journal of Botany, 79, 198-206.

Fernández-Mazuecos, M., Blanco-Pastor, J.L. \& Vargas, P. (2013) A phylogeny of toadflaxes (Linaria Mill.) based on nuclear Internal Transcribed Spacer sequences: systematic and evolutionary consequences. International Journal of Plant Sciences, 174, 234-249.

Fernández-Mazuecos, M., Jiménez-Mejías, P., Rotllan-Puig, X. \& Vargas, P. (2014) Narrow endemics to Mediterranean islands: moderate genetic diversity but narrow climatic niche of the ancient, critically endangered Naufraga (Apiaceae). Perspectives in Plant Ecology, Evolution and Systematics, 16, 190-202.

Francisco-Ortega, J., Santos-Guerra, A., Kim, S.-C. \& Crawford, D.J. (2000) Plant genetic diversity in the Canary Islands; a conservation perspective. American Journal of Botany, 87, 909-919.

Ghebrehiwet, M., Bremer, B. \& Thulin, M. (2000) Phylogeny of the tribe Antirrhineae (Scrophulariaceae) based on morphological and $n d h F$ sequence data. Plant Systematics and Evolution, 220, 223-239.

Gillespie, R.G. \& Clague, D.A.E. (2009) Encyclopedia of Islands. University of California Press, Berkeley, CA, USA.

Guzmán, B., Gómez, J.M. \& Vargas, P. (2015a) Bees and evolution of occluded corollas in snapdragons and relatives 
(Antirrhineae). Perspectives in Plant Ecology, Evolution and Systematics, 17, 467-475.

Guzmán, B., Rodríguez López, C.M., Forrest, A., Cano, E. \& Vargas, P. (2015b) Protected areas of Spain preserve the genetic diversity of Quercus ilex L. irrespective of glacial refugia. Tree Genetics \& Genomes, 11, 124.

Hooker, J.D. (1847) On the vegetation of the Galapagos Archipelago, as compared with that some other tropical islands and of the continent of America. Transactions of The Linnean Society of London, 20, 235-262.

Jaramillo, P. \& Atkinson, R. (2011) Evaluating genetic diversity for the conservation of the threatened Galapagos endemic Calandrinia galapagosa (Portulacaceae). Biotropica, 43, 386-392.

Kalinowski, S.T. (2005) HP-RARE 1 0: a computer program for performing rarefaction on measures of allelic richness. Molecular Ecology Notes, 5, 187-189.

León-Yánez, S., Valencia, R., Pitman, N., Endara, L., Ulloa Ulloa, C. \& Navarrete, H. (2011) Libro Rojo de las plantas endémicas del Ecuador. Herbario QCA, Pontificia Universidad Católica del Ecuador, Quito, Ecuador.

Maunder, M., Culham, A. \& Hankamer, C. (1998) Picking up the pieces: botanical conservation on degraded oceanic islands. Conservation biology for the coming decade (ed. by P.L. Fiedler and P.M. Kareiva), pp. 317-334. Chapman \& Hall, New York, NY.

Miller, M.A., Pfeiffer, W. \& Schwartz, T. (2010) Creating the CIPRES Science Gateway for inference of large phylogenetic trees. Proceedings of the Gateway Computing Environments Workshop (GCE), New Orleans, LA, pp. $1-8$.

Moore, M.J., Tye, A. \& Jansen, R.K. (2006) Patterns of longdistance dispersal in Tiquilia subg. Tiquilia (Boraginaceae): implications for the origins of amphitropical disjuncts and Galápagos Islands endemics. American Journal of Botany, 93, 1163-1177.

Nybom, H. (2004) Comparison of different nuclear DNA markers for estimating intraspecific genetic diversity in plants. Molecular Ecology, 13, 1143-1155.

Petit, R., El Mousadik, A. \& Pons, O. (1998) Identifying populations for conservation on the basis of genetic markers. Conservation Biology, 12, 844-855.

Posada, D. (2008) jModelTest: phylogenetic model averaging. Molecular Biology and Evolution, 25, 1253-1256.

Powell, W., Morgante, M., Andre, C., Hanafey, M., Vogel, J., Tingey, S. \& Rafalski, A. (1996) The comparison of RFLP, RAPD, AFLP and SSR (microsatellite) markers for germplasm analysis. Molecular Breeding, 2, 225-238.

$\mathrm{R}$ Core Development Team (2015) R: a language and environment for statistical computing. $\mathrm{R}$ Foundation for Statistical Computing, Vienna, Austria.

Rambaut, A. \& Drummond, A.J. (2007) Tracer v1.4, Available at: http://beast.bio.ed.ac.uk/Tracer (accessed 10 February 2015).

Rauscher, M.D. (2008) Evolutionary transitions in floral color. International Jounal of Plant Sciences, 169, 7-21.
Rieseberg, L.H. \& Swensen, S. (1996) Conservation genetics of endangered island plants. Conservation genetics. Case histories from nature (ed. by J. Avise and J.L. Hamrick), pp. 305-327. Chapman \& Hall, New York, NY.

Rumeu, B., Vargas, P. \& Riina, R. (2016) Incipient radiation versus multiple origins of the Galápagos Croton scouleri (Euphorbiaceae). Journal of Biogeography, 43, 1717-1727.

Silva, L., Dias, E.F., Sardos, J., Azevedo, E.B., Schaefer, H. \& Moura, M. (2015) Towards a more holistic research approach to plant conservation: the case of rare plants on oceanic islands. AoB Plant, 7, plv066.

Simbaña, W. (2007) Reporte de campo: Monitoreo de Scalesia atractyloides, Galvezia leucantha subsp. porphyrantha y búsqueda de la extinta Blutaparon rigidum en la Isla Santiago. In, p. 1. Fundación Ch. Darwin

Sutton, D.A. (1988) A revision of the tribe Antirrhineae. Oxford University Press, London.

Templeton, A.R., Crandall, K.A. \& Sing, C.F. (1992) A cladistic analysis of phenotypic associations with haplotypes inferred from restriction endonuclease mapping and DNA sequence data. III. Cladogram estimation. Genetics, 132, 619-633.

Traveset, A., Heleno, R., Chamorro, S., Vargas, P., McMullen, C.K., Castro-Urgal, R., Nogales, M., Herrera, H.W. \& Olesen, J.M. (2013) Invaders of pollination networks in the Galápagos Islands: emergence of novel communities. Proceedings of the Royal Society B: Biological Sciences, 280, 20123040.

Traveset, A., Chamorro, S., Olesen, J.M. \& Heleno, R. (2015a) Space, time and aliens: charting the dynamic structure of Galápagos pollination networks. AoB Plants, 7, plv068.

Traveset, A., Olesen, J.M., Nogales, M., Vargas, P., Jaramillo, P., Antolín, E., Trigo, M.M. \& Heleno, R. (2015b) Birdflower visitation networks in the Galápagos unveil a widespread interaction release. Nature Communications, 6, 6376.

Trusty, J.L., Tye, A., Collins, T.M., Michelangeli, F.A., Madriz, P. \& Francisco-Ortega, J. (2012) Galápagos and Cocos Islands: geographically close, botanically distant. International Journal of Plant Science, 173, 36-53.

Tye, A. \& Francisco-Ortega, J. (2011) Origins and evolution of Galapagos endemic vascular plants. The biology of island floras (ed. by D. Bramwell and J. Caujapé-Castells), pp. 89-153. Cambridge University Press, Cambridge.

Tye, A. \& Jäger, H. (2000) Galvezia leucantha subsp. porphyrantha (Scrophulariaceae), a new shrub snapdragon endemic to Santiago Island, Galápagos, Ecuador. Novon, 10, 164-168.

Vargas, P., Roselló, J.A., Oyama, R. \& Güemes, J. (2004) Molecular evidence for naturalness of genera in the tribe Antirrhineae (Scrophulariaceae) and three independent evolutionary lineages from the New World and the Old. Plant Systematic and Evolution, 249, 151-172.

Vargas, P., Ornosa, C., Ortiz-Sánchez, F.J. \& Arroyo, J. (2010) Is the occluded corolla of Antirrhinum bee-specialized? Journal of Natural History, 44, 1427-1443. 
Vargas, P., Heleno, R., Traveset, A. \& Nogales, M. (2012) Colonization of the Galápagos Islands by plants with no specific syndromes for long-distance dispersal: a new perspective. Ecography, 35, 33-43.

Vargas, P., Valente, L.M., Blanco-Pastor, J.L., Liberal, I., Guzmán, B., Cano, E., Forrest, A. \& Fernández-Mazuecos, M. (2014) Testing the biogeographical congruence of palaeofloras using molecular phylogenetics: snapdragons and the Madrean-Tethyan flora. Journal of Biogeography, 41, 932-943.

Vargas, P., Rumeu, B., Heleno, R.H., Traveset, A. \& Nogales, M. (2015) Historical isolation of the Galápagos Carpenter Bee (Xylocopa darwini) despite strong flight capability and ecological amplitude. PLoS ONE, 10, e0120597.

Vekemans, X., Beauwens, T., Lemaire, M. \& Roldan-Ruiz, I. (2002) Data from amplified fragment length polymorphism (AFLP) markers show indication of size homoplasy and of a relationship between degree of homoplasy and fragment size. Molecular Ecology, 11, 139-151.

Webb, C.J. \& Kelly, D. (1993) The reproductive biology of the New Zealand flora. Trend in Ecology and Evolution, 8, 442-447.

Wiggins, I.L. (1968) A new species and subspecies of Galvezia (Scrophulariaceae) from the Galápagos Islands. Occasional Papers of the California Academy of Sciences, 65, 1-7.

Wiggins, I.L. \& Porter, D.M. (1971) Flora of the Galápagos Islands. Standford University Press, Standford, CA.

Wilson, P., Wolfe, A.D. \& Thomson, J.D. (2007) Constrained lability in floral evolution: counting convergent origins of hummingbird pollination in Penstemon and Keckiella. New Phytologist, 176, 883-890.

\section{SUPPORTING INFORMATION}

Additional Supporting Information may be found in the online version of this article:

Appendix S1. Tables S1-S9, Figures S1-S5.

Table S1. Voucher reference and GenBank accession number of 296 samples (196 taxa) of the tribe Antirrhineae and Lafuentea rotundifolia as outgroup.

Table S2. Summary of the results from a pilot study performed to select DNA regions with the highest variation among six Galvezia populations.

Table S3. Sequence of AFLP primers used in this study.

Table S4. Visitors of Galvezia grandiflora and Galvezia leucantha subspp leucantha and porphyrantha.

Table S5. Summary of seven haplotypes based on the plastid spacer $n d h F-r p L 32$ variation of Galvezia spp.
Table S6. Summary of 11 ribotypes based on the nuclear ribosomal ITS variation of Galvezia spp.

Table S7. Summary of the results from a pilot study performed to select the best AFLP primer combination in Galvezia leucantha and the range of markers for the six selected primer.

Table S8. Summary of the results of the autogamy experiment in Galvezia fruticosa and Galvezia grandiflora from Peru.

Table S9. Floral visitors observed at the community of Bahía James (Santiago I., Galápagos), in February 2010 and February 2011 .

Fig. S1. Maximum Clade Credibility chronogram of the nuclear ribosomal ITS and the plastid $n d h F$ gene sequences inferred using BEAST.

Fig. S2. Phylogenetic relationships among 52 individuals (six populations, three subspecies) of Galvezia leucantha from AFLP data using a neighbor-joining analysis of Nei-Li distances and midpoint root.

Fig. S3. Delta K values for STRUCTURE analysis of Galvezia leucantha accessions.

Fig. S4. Pollination network of Bahía James (Santiago I., Galápagos).

Fig. S5. Comparison between the linkage level, specialization and strength of Galvezia leucantha against the mean values observed for the other plants at the community.

Appendix S2. Supplementary Methods and Results.

Fig. S6. Phylogeny of Antirrhineae based on the nuclear ribosomal ITS and the plastid $n d h F$ sequences, using Bayesian Inference (BI).

\section{BIOSKETCH}

A multidisciplinary team of researchers from Spain, Portugal and Ecuador has been studying the threat of invasive species, conservation of endangered plants and plant-animal interactions in the Galápagos Islands since 2006.

Author contributions: P.V. conceived the study; B.G., R.H., M.N., W.S., A.T. and P.V. collected material and data; B.G., R.H. and P.V. analysed the data; B.G. and P.V. wrote the manuscript; and B.G., R.H., M.N., W.S., A.T. and P.V. read and corrected different versions.

Editor: Christoph Kueffer 